\title{
Network Location and Policy-Oriented Behavior: An Analysis of Two-Mode Networks of Coauthored Documents Concerning Climate Change in the Great Lakes Region ${ }^{*,+}$
}

\author{
Ken Frank, I-Chien Chen, Youngmi Lee, Scott Kalafatis, Tingqiao Chen, \\ Yun-Jia Lo, and Maria Carmen Lemos
}

\begin{abstract}
This study explores how a scientist's location in science-based policy networks can affect her policyoriented behaviors. In particular, we hypothesize that those scientists who fill structural holes in their networks will be more likely than others to engage in policy-oriented behaviors. The network data are defined by scientists' coauthorship on policy documents regarding climate change in the Great Lakes. We employ a two-mode network analysis to identify clusters of scientists who coauthored similar documents, and relative to those clusters, we identify those who fill structural holes by bridging between clusters. We find that those scientists who bridged between clusters were more likely to engage in policy-oriented behaviors of policy advocacy and advising than were others in the network. This is an example of a link between network location and policy-oriented behavior indicative of the broader phenomenon of how individuals exert agency, given structural constraints.
\end{abstract}

KEY WORDS: policy behavior, networks, scientists, climate change

\section{Introduction}

The potential threat posed by climate change on socioecological systems has raised the stakes for the role of climate change science in informing policymaking (e.g., IPCC, 2001, 2007; National Research Council, 2009). Yet, despite a growing body of social science focusing on the climate science-policy nexus (Dilling \& Lemos, 2011), less attention has been paid to how existing science diffuses to policy and how climate scientists in diverse fields work collectively to influence climate policy (Bolin,

*Originally presented at the 4th Annual Conference on Political Science, University of Michigan, Ann Arbor, MI, June 14-18, 2011.

'This study is part of the National Oceanic and Atmospheric Administration-funded Great Lakes Integrated Sciences and Assessments (GLISA), which seeks to improve the intersection between science and policy in the Great Lakes region. 
2007; National Research Council, 2009). ${ }^{1}$ Addressing this issue will help us understand knowledge gaps between scientists, decision makers, and the public.

In this study, we seek to inform how knowledge flows from science to policy by studying the role of scientists in brokering between the communities of science and policymakers. We focus on the Great Lakes region, in which the implications of climate change have slowly risen on political and policy agendas. Viewing public document writing as a public and social act, we focus on the relationship between a scientist's location in a network defined by coauthorship of policy documents concerning climate change in the Great Lakes region and the scientist's policy-oriented behaviors.

Analyzing two-mode networks of scientists and the documents they coauthored, we find three distinct clusters of scientists. The limited levels of coauthorship between clusters then constitute structural holes. Previewing our main findings, scientists who filled structural holes by coauthoring documents bridging between clusters were more likely to be engaged in policy-oriented behaviors than were those embedded in a single cluster.

In the next sections we develop our theoretical rationale by integrating the policy literature on scientists as policy brokers with the sociological literature on the advantages to potential entrepreneurs of filling structural holes. We then describe our methods for collecting data from policy documents and web materials, and for analyzing our data by incorporating the results of a network clustering algorithm into a general linear model. We present results of the network analysis showing three distinct clusters, as well as of models of the effect of being a network bridger on policy-oriented behavior. Finally, we comment on the implications of the relationship between network location and policy-oriented behaviors for the application of scientific knowledge to policy, which we interpret as an example of the broader phenomenon of individual action within structural constraint.

\section{The Emergence of Policy-Oriented Behavior}

Our fundamental challenge is to understand policy-oriented behavior relative to broader forces shaping the policy environment. This is an example of the theoretical challenge of characterizing the emergence of action through individual agency within structural constraint (Durkheim, 1964, 1965, 1966; Giddens, 1982, 1984). The scientist as an individual attempts to act by engaging in policy-oriented behavior within the broader structural constraints of the policy arena.

Kingdon $(1984,1995)$ characterizes the broader policy arena in terms of multiple streams (MS) of problem, politics, and policy. In the policy arena, scientists are more likely to influence both the problem stream-as when their science uncovers potential risks to society-and the policy stream by identifying solutions to perceived social problems (Weiss, 1978). However, in the climate change policy arena, especially in the United States, the role of scientists has been particularly salient in the political stream as well (Oreskes, 2011; Pielke \& Sarewitz, 2003) because of the highly contentious political debate about the seriousness, costs, and urgency of climate change as a societal problem. 
In the context of climate change policy, policy-oriented behavior may carry unusually high stakes for scientists professionally and personally (Dilling \& Lemos, 2011). For example, scientists seeking to engage policy regarding climate change may have their "neutrality" questioned and may be expected to perform activities that are costly both in terms of emotional commitment and time (Lemos \& Morehouse, 2005; Montpetit, 2011; Pielke \& Sarewitz, 2003). Scientists may also personally find it challenging to enter a policy arena characterized by competing coalitions (JenkinsSmith \& Sabatier, 1994; Sabatier \& Jenkins-Smith, 1993; Weiss, 1978). For example, in the case of climate change, the highly contentious debate across partisan and cultural lines has created a virtual battlefield across which different coalitions/networks battle for the support of the public and other powerful coalitions (Nisbet, 2009).

As a result of the challenges scientists face in participating in policy related to climate change, many scientists may shy away from, or drop out of, the policy arena (Sabatier \& Zafonte, 2001). Those scientists who do participate in the climate change arena might possess unusual attributes such as comfort with contentious issues, willingness to take risks, or strong identification with an issue (Kingdon, 1984; Polsby, 1984; Roberts \& King, 1991). On the whole, scientists who participate in climate change policy may be more entrepreneurial than others, willing "to invest their resources-time, energy, reputation, and sometimes money-in the hope of a future return" (Kingdon, 1995, p. 122).

Beyond individual attributes, there may be other factors about a scientist's context that affect her participation in policy-oriented behavior. In particular, the networks in which scientists are embedded may be critical to supporting entrepreneurial behavior (Kingdon, 1984, 1995). These networks can provide scientists with information or support that can be valuable in a contentious realm (Burt, 2005). In fact, previous research has shown that entrepreneurs know how to use information that inheres in their networks to push their policy agendas (see also Balla, 2001; Mintrom, 1997; Mintrom \& Norman, 2009; Mintrom \& Vergari, 1998; True \& Mintrom, 2001).

In this study, we seek to specify the particular elements of a network that can support a scientist's policy-oriented behavior. To do so, we draw on Burt's theories of structural holes (Burt, 1992) and network brokerage (Burt, 2005). Consider Burt's $(1992,2001)$ iconic representation in Figure 1, in which a hole is created by the dense ties within clusters A, B, and C, and sparse ties between them. As such there is limited interaction between members of the different clusters, and therefore little potential for information sharing or coordination between clusters. An actor such as Robert who fills the hole by bridging between the clusters can have distinct advantages (Burt, 2005). For example, buyers of goods who are connected to otherwise separate sellers can negotiate lower prices, and mid-level managers who bridge between different divisions are more able to access diverse information and therefore more likely to be successful within their firms (Burt, 2001).

Here we apply Burt's theory of structural holes and bridging to the policy domain. Just as businesspeople can gain strategic advantage by bridging between structural holes, so too can scientists as they gain access to unique information and opportunities by bridging between cohesive subgroups (Balla, 2001; Kingdon, 1984; Mintrom, 1997; Mintrom \& Norman, 2009; Mintrom \& Vergari, 1998; True \& 


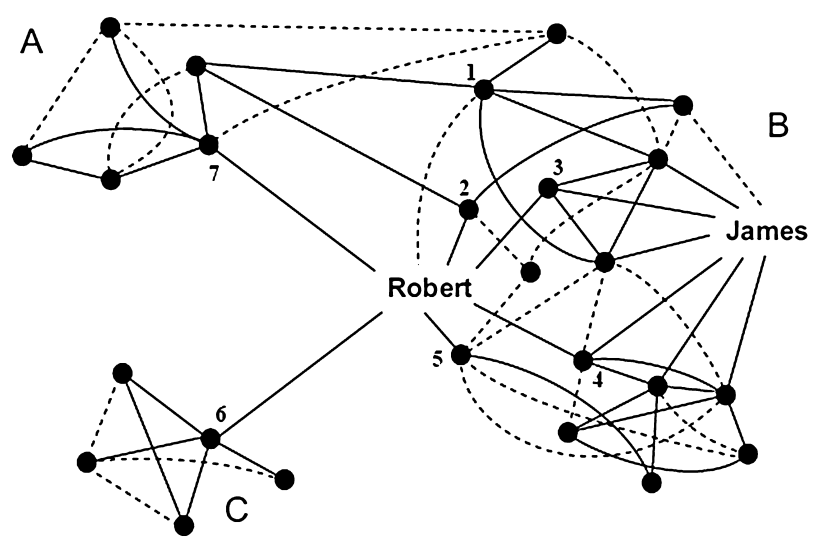

Figure 1. Robert Fills a Structural Hole in the Network.

From: Mauro F. Guillen, Randall Collins, Paula England, and Marshall Meyer, eds. "The Social Capital of Structural Holes," in New Directions in Economic Sociology (New York: Russell Sage Foundation, 2002).

Mintrom, 2001). Each time a scientist contributes to a policy discussion, she is exposed to the language and culture of that domain, including the policy-oriented elements (Montpetit, 2011). Scientists who engage in multiple domains may accumulate an advantage by capitalizing on each investment in brokering between science and policy, and by learning the contexts of different domains (Burt, 2007). They can then use this advantage to advocate for policies they endorse. Therefore, we hypothesize:

Hypothesis 1: Scientists who bridge between clusters of actors will be more involved in policy-oriented behavior than other scientists embedded in a single cluster.

In our study we will identify two dimensions of policy-oriented behavior. First is advocacy, defined as the extent to which actors engage in different activities with an intention to influence policy and behavior. This behavior represents the role of the scientist as entrepreneur, pursuing policies which she endorses.

Second, scientists may engage in policy advising, defined by directly informing policies or plans (e.g., contributing solutions, participating in policy design) with research about climate change and expert knowledge. Scientists who participate in policy advising across clusters can gain unique knowledge that will have benefit for the collective (Berardo \& Scholz, 2010; Diani, 2003), with systemic implications for the diffusion of innovations or coordinated behavior (Durkheim, 1964; Homans, 1950; Simon, 1965; Valente, 1995). In turn, policymakers may recognize the potential of bridging actors and tap them for policy advising (Berardo \& Scholz, 2010).

Our hypothesis implies a causal direction: that being a bridger in part contributes to policy-oriented behavior. Alternatively, it could be that a policy-oriented disposition causes an actor to both become a bridger and to become involved in policy. That is, one's position in a network may be confounded with a policy-oriented disposition. Or perhaps there is a more nuanced dynamic in which participation in different kinds of policy arenas exposes actors to different organizations and 
environments from which they draw for support to engage in policy-oriented behavior (e.g., Davis, McAdam, Scott, \& Zald, 2005; Diani \& McAdam, 2003). We explore these concerns about causality using qualitative data and contribute to scientific discourse by quantifying how strong a causal mechanism (e.g., policy-oriented disposition) must be to invalidate our inferences.

\section{The Emergence of Policy-Oriented Behavior within Two-Mode Networks of Coauthored Documents}

Our hypothesis links the role of bridging in a network to policy-oriented behavior. But the role of bridging must be defined relative to subgroups in a given network (Gould \& Fernandez, 1989). In this study, we define subgroups in terms of clusters of scientists who cowrote common policy-related documents related to climate change in the Great Lakes region. We focus on documents because they represent one of the fundamental activities through which actors such as scientists seek to influence public opinion and policy. Indeed, the role of science in policy-related documents is recognized in the goals of the first four Intergovernmental Panel on Climate Change (IPCC) assessments (Bolin, 2007).

Although each time a scientist contributes to a policy document he acts as a broker between science and policy, the pattern of coauthorship varies across scientists. Some scientists participate in a single document, as a vehicle for packaging an isolated set of findings to be policy relevant. Others participate in multiple documents, but in a fairly narrow domain of time and location. Still others participate in multiple documents that pertain to different domains.

Our goal then is to study the relationship between policy-oriented behavior and location in networks defined by the coauthorship of policy documents. In particular, we test the relationship between the role of bridging in the document coauthoring network and policy-oriented behaviors in the policy domain. In the next section, we present our data and methods including Field, Frank, Schiller, Reigle-Crumb, and Muller's (2006) technique for characterizing social structure in terms of clusters in two-mode network data.

\section{Data}

\section{Network Data}

The document database was generated through successive web searches using Google. We paired keywords including "stakeholder," "adaptation," "impact," and "workshop" each with the phrase "climate change great lakes." We then expanded our search by "snowballing" from the initial crop of documents to build our document sample. For example, if we found a document published under the coordination of NOAA or the Union of Concerned Scientists, we looked through their publications to identify cited references that were relevant (e.g., concerning climate change in the Great Lakes). The document search was completed by the middle of December 2010. Most documents were produced exclusively about and for the Great 
Lakes region but a few national and international scale documents were included that directly addressed the Great Lakes region. Authorship included any recognized contribution to original text (including lead authors, coordinating authors or contributing authors, but not acknowledgments).

The original data consisted of 71 documents coauthored by 1,762 actors. The majority of actors came from governments or academic institutes located in the United States and Canada, but some were affiliated with NGOs or the private sector. Because our focus is on location in the network structure, actors who authored only one document were considered affiliated with that document alone, and not part of the broader network of actors who coauthored multiple documents. Eliminating actors who authored only one document, our final analyses consisted of 22 documents coauthored by 79 actors.

Note that although policy-oriented behaviors could emerge from contributing to a document, there may well have been less observable precursors of such behaviors. Furthermore, there may have been delays in publications and unobserved professional interactions that might have been associated with the production of a document. Therefore, we use the documents as general indicators of professional interactions leading up to the production of the document, but not necessarily confined to the year the document was published.

\section{Individual Measures}

Data to characterize the policy-oriented behavior of the 79 actors were obtained from their professional web sites and curriculum vitae. ${ }^{2}$ Three researchers trained for this project collected information such as affiliations, memberships, publications / reports, and so on. To assess the reliability of our coding, 20 (25.3 percent) of the actors were sampled to be coded by two raters. Corresponding to our two components of policy-oriented behavior, we developed measures of policy advocacy and policy advising.

Policy Advocacy. The activities defining policy advocacy included meetings to raise awareness of climate change issues, media campaigns regarding climate change issues, conferences and workshops that engaged decision makers, interviews, press conferences, and columns in national or local newspapers or blogs to increase awareness of climate change and advocate climate change-related action. The score for policy advocacy regarding climate change ranged from 0 to 4 (5 scales). If there was no evidence that the actor was involved in policy advocacy activity, the score was 0 . If the actor's reports or publications were intended to be policy relevant (i.e., expressed the intention or claim that the document could inform policy), the score was 1 . If the actor's activities were related to policy advocacy, but advocacy was not their primary activity, the score was 2 . If policy advocacy was a primary activity at some point in the scientist's life, the score was at least 3 . If the actor was consistently involved in policy advocacy over time, the score was 4 . Agreement within one unit on policy advocacy was approximately 45 percent on a subset of 20 actors primarily 
due to differences in identification of relevant information on web pages (85 percent were within 2 units). Therefore, two raters were assigned to score each actor, and any differences were reconciled through discussion.

As an example of our coding, consider actor 259, who participated in the following exchange on the BBC's "Your World Today" (January 29, 2007; found at http:/ / transcripts.cnn.com/TRANSCRIPTS/0701/29/ywt.01.html):

Interviewer: Now, we have reports coming out, scientists around the world warning that the impact of these higher temperatures could be devastating for humankind. But yet, you know, we still see people driving their SUVs, $\mathrm{CO}_{2}$ levels-very high levels, of course, around the world. What needs to be done to change minds, in your opinion as a scientist?

Actor 259: I think it's important that people connect the evidence we're seeing with their own actions. Examples like in the very hot summer in Europe in 2005, there were over 30,000 extra deaths due to the extra warming. People need to understand that that's the kind of phenomenon that we're going to see more and more as the earth's temperature continues to warm.

Actor 259 could have responded that as a natural scientist he did not have a scientific opinion about changing human behavior. Indeed, many of the non-policyoriented actors did not publicly comment on issues beyond their scientific focus (e.g., actors 649 and 1657). But actor 259 emphasized the importance of social action for mitigating climate change: "I think it's important that people connect the evidence we're seeing with their own actions." In this sense he was playing an advocate role. Furthermore, based on his personal history, actor 259 was continuously involved in policy advocacy regarding climate change. Therefore, actor 259 was assigned a score of 4 on policy advocacy.

In contrast to actor 259 , consider actor 649 , who worked at a private organization conducting research on energy and environmental technology and policy, responses to global climate change, and sustainable development. In response to his own rhetorical question: "How should we respond or adapt to the anticipated impacts of global warming, especially as they impinge on infrastructure?" He wrote (Actor 649, 2010):

Note that the question is not whether we should adapt to climate change, because we necessarily will adapt. The question facing the engineering profession is whether adaptation will be a planned, studied response or a haphazard reaction to events as they unfold. In many ways, adaptation is classic risk management, but it is complicated by the inherent uncertainties associated with climate change. The terms of the risk analysis include: the hazards of concern (sea level rise, stronger storms, and heat waves); vulnerable assets (transportation infrastructure and its value to the economy); potential consequences (direct and indirect); and the likelihood or probability that a hazard will occur. 
Note that actor 649 's response focuses on the engineering technology for adaptation without the emphasis on public opinion or policy. Combined with a lack of evidence of political activity in publicly available documents or on his web site, Actor 649 's score on policy advocacy was 0 .

Policy Advising. To generate scores on policy advising, we applied the same scale and rubric as used for policy advocacy to the policy advising activities, for example, participating in policy-related committees or governmental meetings. For policy advising, 95 percent of the scores on a subset of 20 actors were in agreement within one unit (e.g., scores of 3 and 4 were within one unit and therefore considered to agree). Therefore, only one rater was used to score each of the remaining actors. As an example of how we coded policy advising, return to actor 259 who was involved in many national and international committees related to global ecology and climate change including the IPCC, whose goal is to inform United Nations Framework Convention on Climate Change (UNFCC) governments about climate change. Based on this information, his policy advising score was assigned a value of 4 .

To help interpret causal inferences we made from data from the documents and web sites, we interviewed 10 bridging actors and 4 nonbridging actors using a protocol (see Appendix A) based on Frank, Zhao, and Borman (2004) and Monteleone (2011). The protocol was tested with several subjects not in our sample, revised, and then administered through phone interviews during February 2012 and then early April 2012. The protocol focused on how and why scientists became involved with working on climate change policy and how involvement in collaborative efforts with decision makers influenced scientific and policy-oriented behaviors. While we encouraged interviewees to respond specifically to their experiences in document production, we also incorporated responses concerning their more general experiences.

\section{Methods}

\section{Identifying Clusters in Two-Mode Network Data}

We began our network analysis by identifying clusters of actors who coauthored common documents. Relative to these clusters, we then identified those who bridged between clusters, and assessed whether occupying the role of broker in the social system was related to policy advocacy and advising.

To identify clusters of scientists who coauthored documents, we employed Field et al.'s (2006) clustering algorithm for two-mode network data. This algorithm adapted Frank's (1995) clustering technique for one-mode network data (e.g., who talks to whom) to two-mode data (e.g., who authors which documents). In particular, the algorithm assigns actors and documents to clusters by maximizing the odds ratio (AD/BC) from Table 1 . That is, it maximizes authorship within clusters (cell D) and lack of authorship outside clusters (Cell A). Conversely, it minimizes the off-diagonal elements: lack of authorship on documents within the 
Table 1. Association between Membership in the Same Cluster and Authoring a Document

\begin{tabular}{llcc}
\hline & & \multicolumn{2}{c}{ Authorship of Document } \\
\cline { 3 - 4 } & & No & Yes \\
\hline Cluster membership & Different & A & B \\
& Same & C & D \\
\hline
\end{tabular}

cluster (cell C), and authorship of documents in different clusters (Cell B). By iteratively reassigning actors to clusters to maximize the odds ratio, each cluster ultimately contains a set of actors (e.g., authors) as well as the focal activities (e.g., documents) in which they participate.

To link the clustering algorithm to current models for two-mode network data (e.g., Skvoretz \& Faust, 1999; Wang, Sharpe, Pattison, \& Robins, 2009), note the odds ratio of Table 1 can be interpreted in terms of a logistic regression. Define $\theta_{1}$ from the following model:

$$
\log \left(\frac{p\left[x_{i j}=1\right]}{1-p\left[x_{i j}=1\right]}\right)=\theta_{0}+\theta_{1}{\text { same } \text { cluster }_{i j}}
$$

where $x_{i j}$ takes a value of 1 if actor $i$ was an author on document $j, 0$ otherwise; and same cluster $_{i j}$ takes a value of 1 if actor $i$ and document $j$ are assigned to the same cluster, 0 otherwise. Thus, the criterion the algorithm maximizes to identify latent clusters is the same criterion, $\theta_{1}$ in (1), used to evaluate the salience of known groupings on actor-even participation.

Using Field et al.'s (2006) adaptation of Frank's (1995) KliqueFinder algorithm to maximize $\theta_{1}$ has two practical advantages for identifying clusters in our data. First, $\theta_{1}$ represents a tendency but not an absolute criterion. As a result, variation in the data need not be accommodated by constructing overlapping clusters-the algorithm identifies nonoverlapping clusters. We can then identify bridging relative to membership in these nonoverlapping clusters.

Second, the algorithm dynamically identifies the number of clusters "on the fly"; therefore, researchers need not specify the number of clusters a priori, nor must they interpret and choose among multiple clustering solutions according to subjective criteria. This feature also enables us to use simulations to test the statistical significance of the clusters.

Having defined the clusters, 22 actors were then defined as bridging between clusters if they authored at least one document in more than one cluster. Differences between the bridgers and others were tested using basic $t$-tests as well as linear models that controlled both for cluster membership and sector (e.g., nonprofit, public). We then coded our qualitative data for the basis of policy-oriented behaviors to evaluate our inferences, and we quantified the robustness of our inferences to unobserved variables. 


\section{Results}

\section{Clusters and the Role of the Broker}

Results of application of the algorithm to data concerning documents and their coauthors are shown in Figure 2 (see technical Appendix B for details of document names). ${ }^{3}$ In this figure, diamonds represent documents, and circles represent actors. Lines from an actor to a document indicate the actor was an author on the document. The large ovals indicate cluster boundaries as identified by the algorithm.

In Figure 2, we observe three clusters, with approximated simulations indicating statistically significant evidence of clustering (see Field et al., 2006). Each cluster contains a mix of those employed as academics, in the nonprofit sector, and in the private sector (as indicated by the pie charts). This mix shows how the focal activities within each cluster establish venues for brokerage between scientists and policymakers.

The publication date of the documents gives a sense of the timing of the emergence of each cluster.

Cluster 1 (prior to 2003):

Preparing for a Changing Climate (20040);

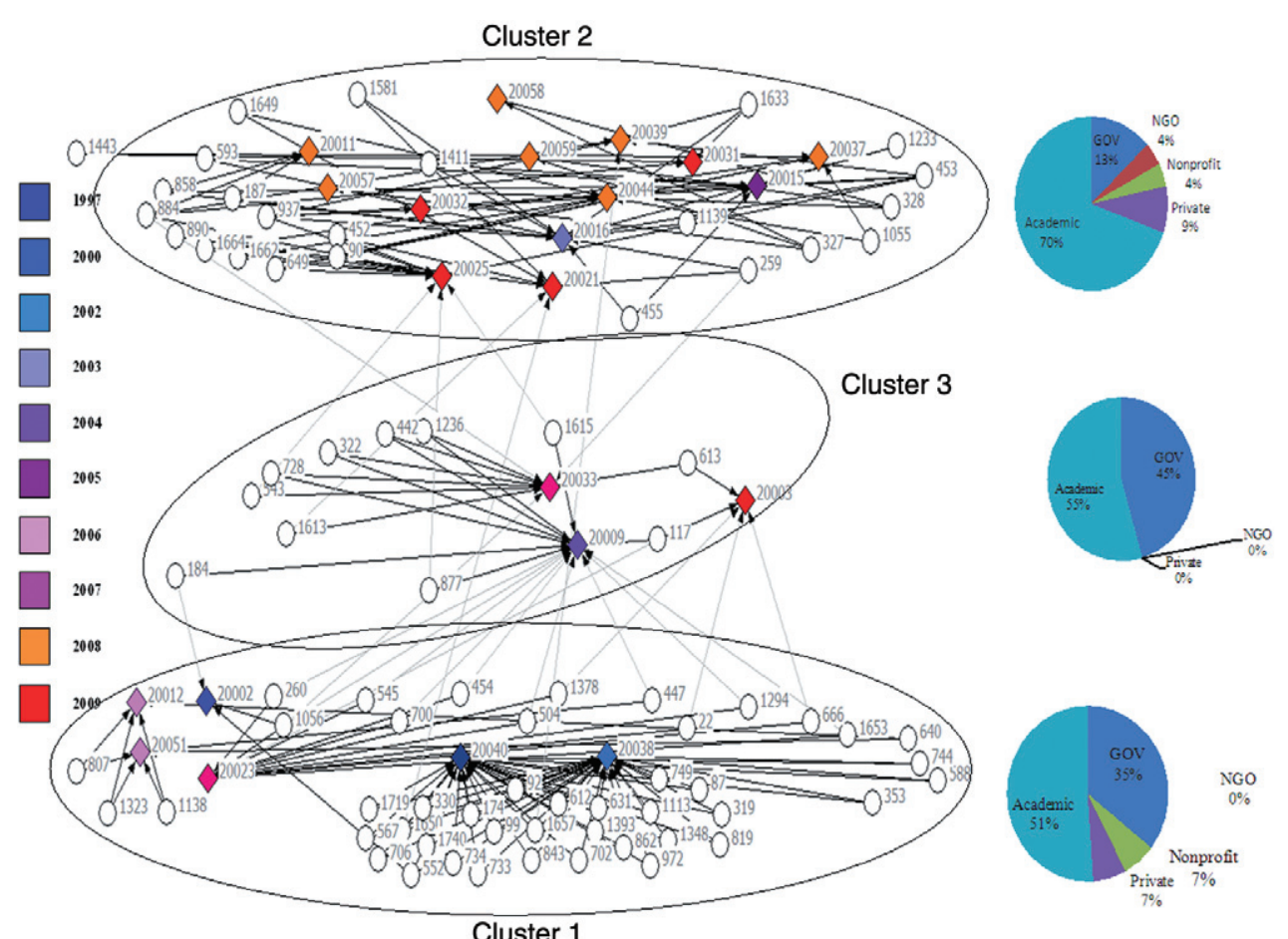

Figure 2. Clusters in a Two-Mode Network of Actors and the Documents They Coauthored. 
Adapting to Climate Change and Variability in the Great Lakes-St. Lawrence Basin (20002); and

Preface to the Potential Impacts of Climate Change in the Great Lakes Region (20038).

Cluster 2 (2002-2005):

Confronting Climate Change in the Great Lakes Region (20015);

Confronting Climate Change in the Great Lakes Region (20016).

Cluster 3 (2004):

Climate Change Impacts and Adaptation: A Canadian Perspective (20009).

Structural "holes" were manifest once the focal points for each cluster had been established by 2005. After this point, new policy documents were written that were authored by members of existing clusters that opened up opportunities for bridging, because actors could affiliate with one cluster while coauthoring documents in other clusters. For example, document 20003 in cluster 3 attracted authors from cluster 1, and documents 20025 and 20021 in cluster 2 attracted authors from clusters 1 and 3. For example, actor 1615 in cluster 3 bridged with cluster 2 when he coauthored "Global Climate Change Impacts in the US" (document 20025 in cluster 2, published in 2009).

We now use the definition of bridgers defined relative to the clusters to examine differences between the bridgers and others in the network on policy-oriented behavior. The mean level of advocacy was 2.15 for bridgers versus 0.7 for others (on our scale from 0 to 4 ). The difference of $1.45 \mathrm{had}$ a standard error of 0.33 ( $p \leq 0.0001)$. Controlling for differences among clusters and sector, the bridgers were more likely to engage in political advocacy (estimated difference of 1.56, standard error of 0.34 , $p \leq 0.0001)$.

On the second dimension of policy-oriented behavior, the bridger's mean scores for policy advising were 3.6 versus 2.4 for others, with standard error for the difference of about 0.36 ( $p \leq 0.002)$. Controlling for differences among clusters and sector, the bridgers were more likely to be involved in policy advising (estimated difference of 1.30, standard error of $0.34, p \leq 0.001$ ). Combined, these analyses are consistent with our general hypothesis that scientists who bridge between clusters of actors will be more involved in policy-oriented behaviors than other scientists embedded within a single cluster.

\section{Sensitivity of Results to the Location of Document "From Impacts to Adaptation" in Cluster 1}

Note that "From Impacts to Adaptation" (document 20023) is located in cluster 1 because of a single long chain (through actor 1056, who also coauthored document 20002, which was coauthored by 552 who coauthored 20038, one of the core documents in cluster 1). While the location of "From Impacts to Adaptation" maximizes Field et al.'s (2006) clustering criterion, its location would be different if any link in the chain were severed. Moreover, many of the bridging actors $(22,260,447,454,504$, $545,666,700,1294,1378$, and 1653) were labeled as such because they were coauthors 
on "From Impacts to Adaptation." Therefore, we examine the sensitivity of our analysis to the location of "From Impacts to Adaptation" in cluster 1.

If bridging actors 22 through 1653 were not included in our analysis, we would have made the same inference regarding the relationship between bridgers and advocacy ( $p \leq 0.03$ without controls, $p \leq 0.052$ with controls). Similarly, if bridging actors 22 through 1653 were not included in our analysis, we would have inferred that bridgers were different from others in their level of policy advising ( $p \leq 0.03$ without controls, $p \leq 0.10$ with controls). In this sense, our inferences regarding the relationship between bridging and policy-oriented behavior are fairly robust with respect to the most tenuous assignment made by the algorithm (based on the long chain locating "From Impacts to Adaptation" and the designation of actors 22 through 1653 as bridgers).

\section{Interview Responses Regarding the Basis of Involvement with Climate Change}

From our statistical analysis we do not know whether the bridging role was preceded by a policy-oriented disposition. It may be that those with a policyoriented disposition engaged in a bridging role as well as policy-oriented behaviors-the disposition is the causal agent, and not the location in the network. To explore this issue, we draw on the interviews of the subjects, in particular focusing on factors that they described as affecting their policy-oriented behaviors. Many of the scientists we interviewed $(22,259,504,1378,1613,1615,1650)$ indicated that their participation in the documents was solicited and supported by government agencies. For example, actor 259 indicated that for the IPCC, he "was asked by the U.S. government" to participate. This might suggest an exogenous factor in determining bridging, with any resulting differences in policy-oriented behavior attributable to the bridging role and not the characteristics of the individuals. But further inspection shows that solicitations are based on subjects' careers (as manifest in their curricular vitaes) and the niches they serve on the authoring committee. For example, actor 22 stated:

It's obvious once somebody is looking for someone to take part in the processes that my name would come up given my experiences. Doing this type of work is all about process. My personal background is key.

Similarly, actor 259 explained that "For the Great Lakes I had worked on a California report earlier and had experience." Furthermore, a number of those we interviewed implied that agreement to become an author may well depend on their own personal attributes, especially the desire to see science applied to policy. For example, actor 1650 stated "I have always felt that scientists don't have the right to sit in an ivory tower. I didn't want to work on things not used by people."

Although the previous responses suggest that at least for some scientists, personal motivation is an important factor affecting policy-oriented behavior, location in the social structure may also matter. Consider actor 877's detailed description of how he became involved in issues regarding climate change: 
I can take it back to a bus conversation in 1976. A NOAA scientist talked about Keeling and the Mauna Loa measurements. I got involved in global change, I got involved with climate in the second world conference, then the Canadian climate research program. The Toronto Conference in 1988atmosphere, other meetings in the late 1980s, then the creation of the IPCC. These were through scientists raising a warning, bringing it to the attention of governments.

Note that engagement began with a conversation between scientists, in this instance afforded by a shared bus ride. On the other hand, actor 877 also described his individual motivation: "I got involved in global change. I got involved with climate in the second world conference."

Structurally, actor 877's involvement in multiple public policy projects located him as a bridge between clusters 1 and 3, and he later noted "there isn't a boundary between the scientists." Ultimately, actor 877 engaged in considerable policy advising- "I worked at the science/policy interface, it's important to understand the science and bring it to policymakers in ways they can use." In summary, actor 877's description is consistent with the conception of policy-oriented behavior as emerging out of the confluence of individual agency and structural conditions (Durkheim, 1964, 1965, 1966; Giddens, 1982, 1984).

While we cannot be certain that actor 877's policy-oriented behavior was caused by his network position emanating from the bus ride and in his participation on multiple documents, we can imagine that it would have been more difficult if his position as a network bridger had not exposed him to opportunities to pursue policy-oriented behaviors. This can be understood by comparing the current outreach and policy contexts with insularity in the past as described by a nonbridging actor 374:

In the last ten years or so it's become obvious that we need to engage more with other groups, especially scientists. Our organization especially was too insular ten years ago. The issue of climate change has been one of the drivers of realizing that and making an effort to change it.

Even if actors like 374 perceive that reaching across gaps and expanding one's network can be valuable, the specific structural pattern that relates to policy-oriented behavior may not be perceived by the scientists themselves. As 1378 (who bridges between clusters 1 and 3 and was assigned level 4 of advocacy and advising) stated, "I can't really tell you what interactions have pushed future involvement and what haven't."

\section{Quantifying the Robustness of Our Inferences}

Given the ambiguity of our inference and the uncertainty of even some scientists about the effect of location in the network on policy-oriented behavior, we recognize that there will be debate about our inference of an effect of a bridging network position on policy-oriented behavior. Here we seek to quantify the terms of that 
debate as a form of sensitivity analysis (e.g., Copas \& Li, 1997; Robins, Rotnitzky, \& Scharfstein, 2000; Rosenbaum \& Rubin, 1983). To do so, we draw on Frank's (2000) definition of the impact of a confounding variable on an estimated regression coefficient. Frank (2000) defines the impact of a confound as $r_{y v} \times r_{x v}$, where $r_{y v}$ is the correlation between a confounding variable, $v$ (e.g., predisposition to be policy oriented), and the outcome $y$ (e.g., policy advocacy), and $r_{x v}$ is the correlation between $v$ and $x$, a predictor of interest (e.g., bridger). Defining impact as impact $=r_{y v} \times r_{x v}$, Frank (2000) then quantifies how large the impact of an omitted variable must be to invalidate an inference.

Using Frank's calculations, the impact $\left(r_{y v} \times r_{x v}\right)$ of an omitted variable would have to be greater than 0.3 to invalidate our inference of an effect of the role of bridger on policy advocacy. Implied, the correlation between the confound and being a bridger $\left(r_{x v}\right)$ and the correlation between the confound and policy advocacy $\left(r_{y v}\right)$ would each have to be greater than 0.54 to invalidate our inference $(0.54 \times 0.54=0.29)$. Similarly, the impact of a confound would have to be greater than 0.16 , with component correlations of 0.4 , to invalidate the inference of an effect of the role of bridger on policy advising. Such correlations are moderate to large by social science standards.

As a basis for interpreting the impact thresholds reported in the previous paragraph, a recently reported correlation between $\mathrm{CO}_{2}$ and global temperature was roughly 0.31 (taking data 51 data points from 1958 to 2009), controlling for autocorrelation (Tunnicliffe Wilson, 2010). This correlation is statistically significant, with t-ratio of roughly 2.31. Calculating Frank's (2000) impact threshold, the impact of a confounding variable would have to be 0.057 (with component correlations of 0.238 ) to invalidate the inference of an effect of $\mathrm{CO}_{2}$ on global temperature. By comparison, the impact of omitted variable to invalidate our inference regarding bridgers would have to be approximately three times greater than the impact necessary to invalidate Tunnicliffe Wilson's inference of an effect of $\mathrm{CO}_{2}$ on temperature (although to be fair, Tunnicliffe Wilson's analysis controls for autocorrelation effects, considerably diminishing the relationship between $\mathrm{CO}_{2}$ and temperature, while our analysis does not include similar time series-based controls). ${ }^{4}$

\section{How Authoring Documents Can Shape Policy Involvement}

Even if the effect of bridging on policy-oriented behaviors is uncertain, the interviews indicate that authoring policy documents, and having multiple opportunities to do so, could shape subsequent policy-oriented behaviors. For example, actor 454 stated:

Participating in "From Impacts to Adaptation" had a very strong influence on the development of our subsequent adaptation programming. Most specifically, it was the rationale for the shift in our program emphasis away from research and generation of new knowledge to the development of tools and facilitating collaboration for the application of adaptation knowledge. The 
issues addressed by our Regional Adaptation Collaboratives program all emerged from the 2008 assessment.

My perspective was broadened as a result of developing the two reports referenced, particularly with respect to social and economic processes as drivers of adaptation action. Developing the reports helped to focus my attention on the policy/decision drivers that provide the opportunity to mainstream adaptation, and enhance my ability to communicate with decision-makers.

Actors 22, 504, 1378, 1613, and 1650 expressed similar sentiments. Picking up on the importance of language for bridging (Burt, 2007), actor 1615 stated:

Climate change is climate science but there is more to it. Some people are good at plain English, but need different people for communicating different things. I have learned that this translation is a very inter-disciplinary challenge.

Notably, actors 259 and 1615 did not endorse this interpretation, indicating that their scientific pursuits were not strongly influenced by authoring policy-related documents.

\section{Discussion}

The application of knowledge about climate change to the policy realm can be filtered by the process of producing policy documents (e.g., Bolin, 2007). Here we suggest that a by-product of document production is the shaping of networks of scientists who may broker between the scientific and policymaking communities. And this shaping is not solely a function of authoring a single document. We believe it is a function of the scientist's position in the network of those who coauthored sets of documents in a common domain. Ultimately, our results are consistent with a link between network position and policy-oriented behavior; scientists who bridged between clusters of coauthors were more likely to engage in policy-oriented behaviors than were those whose authorship was confined within a single cluster.

The potential salience of a scientist's position in the social structure offers important insights into the classic micro-macro tensions of agency and structural constraint (e.g., Durkheim, 1964, 1965, 1966; Parsons, 1949; Sewell, 1992; Wrong, 1961). The challenge then is to describe how individuals contribute to the formation of the institutions and structures that ultimately constrain (or enable) them (Giddens, 1982, 1984). In this study, the structures are the clusters of scientists who coauthored common documents related to climate change in the Great Lakes region.

The clusters defining the social structure were not formal or stable entities deliberately established by external agents. Nor was the social structure completely determined by individual action. The social structure emerged through the pattern of scientists' choices, constrained by opportunities created by the policy documents sponsored by policymakers. In particular, the social structure that emerged included 
structural holes created by the formation of each cluster around focal documents by 2006. It was then a scientist's bridging between these emergent holes that was linked to policy-oriented behavior.

\section{The Bridging Scientist versus the Business Entrepreneur}

Our finding that bridging was linked to policy advocacy and advising offers important commentary on the sociological and business literature regarding structural holes. The bridger is like her business counterpart when she engages in policy advocacy, because she is essentially promoting her individual position. But the bridger is different from her business counterpart because her unique access to information allows her to contribute to the social system as she engages in policy advising. In contrast, the business entrepreneur exploits her network advantage by inhibiting efficient resource flows in the market, to the detriment of the system.

The differences between the bridger in the business and policy realms has implications for the generality of the role. A bridger in the business realm may exploit his position for multiple advantages, ultimately contributing to profitability through multiple revenue streams. But in the policy realm, bridgers may be defined relative to specific issues. Those who bridge in networks concerning climate change in the Great Lakes region may not be the same as those who bridge in networks focused on water usage, or climate change in other regions. This implication provides an incentive for climate scientists to cooperate, as those who gain a competitive advantage through their network position related to one issue may not know what their position will be relative to future, unknown issues (Rawls, 1971).

\section{Limitations and Future Work}

Causality. Debate about our inferences is inevitable, as pertains to studies of many social phenomena (e.g., Abbott, 1998). In this study we respond by drawing on our qualitative data to interpret our inference. It could be that those who seek to engage in policy-oriented behaviors realize they will need a diverse network to do so, and therefore position themselves as bridgers. At the very least then, we have identified a profile of the policy broker as one who engages in bridging ties in her own network, which shapes her context as she engages in policy-oriented behaviors.

More generally, we call upon further research to disentangle the causes and effects of network position and policy-oriented behavior. This could be accomplished by studying phenomenon in which network structure and policy-oriented behavior can be temporally separated, in which case one could model changes in policy-oriented behavior as a function of network position at baseline. Or one could study the effects of network brokerage in laboratory settings with randomized assignments (e.g., Cook \& Whitmeyer, 1992). Even so, debates about inferences could be challenged based on concerns about omitted variables or the representativeness of a sample. Therefore, we encourage researchers and policymakers to debate causal inferences in the quantitative terms of the conditions necessary to invalidate the inference (e.g., Frank, 2000). 
Scope. We have anchored our analysis in documents written about climate change in the Great Lakes region. It is unclear whether policy-oriented behavior could be linked to network position in other contexts. For example, it is possible that in systems with more top-down decision making and reliance on scientific management, there would be a convening of scientists to inform policy (Weible, Sabatier, \& Lubell, 2004). This would create a core network, and the role of bridgers would be less salient.

We also do not know the extent to which network roles would be related to policy-oriented behavior in other domains. Certainly Kingdon (1995) and others generally alluded to the importance of resources that inhere in networks for policyoriented behavior. Therefore, those who occupy bridging roles could gain a competitive advantage in almost any domain. The critical issue is the value of the resources, such as information, that actors can access through their role as bridgers versus through other means (e.g., trial and error, scientific study). We encourage others to examine the relationship between network position and policy-oriented behaviors in different decision-making structures and domains.

Document Content. In this study we have not analyzed the content of the documents. Recognizing the agency of document authors, there is likely a dynamic interplay between the content of the documents and authorship. As more policy-oriented scientists contribute to authorship, the language and foci of the documents may change. Indeed, there are general patterns in the documents that suggest that perceptions about addressing climate change have evolved in the last several years. Documents produced since 2007 were less focused on measuring impact trends and more focused on the process of developing tangible, actionable policy responses than those published before (for more explanation, see Lemos \& Kalafatis, 2011).

\section{Implications for Practice: Cultivating Policy-Oriented Behavior}

While our analysis is not a direct evaluation of a program, our findings can guide practice. Generally, scientists and policymakers engaged in climate change should consider that future advocates and advisors are more likely to be engaged in bridging between domains than others in their networks. Drawing on this finding, individuals seeking to engage in policy-oriented behavior could strategically position themselves to bridge between domains (Burt, 2005). Individuals might even be able to identify potential adversaries or allies, given locations relative to structural holes in the social structure.

On a broader scale, government agents seeking to mobilize the research community should consider the distribution of bridgers, and whether it is adequate to sustain the policy-oriented behaviors they desire. If deemed inadequate, sufficient opportunities should be created for actors to bridge between domains. In the example of climate change policy in the Great Lakes region, one might attend not only to balancing the composition of authors on a single document, but also to balance opportunities for bridging across documents. Undoubtedly some 
policymakers are already aware of the importance of network structure, and perhaps are leveraging it. At the very least then, we have described behaviors that others might emulate.

\section{Conclusion}

As we have demonstrated a link between network position and policy-oriented behavior, we have provided a glimpse into the processes through which scientists contribute to policymaking. The general context may be shaped by the multiple streams of problem, politics, and policy (Kingdon, 1984). And within the policy realm, there may be competing coalitions that shape scientists' involvement (JenkinsSmith \& Sabatier, 1994; Sabatier \& Jenkins-Smith, 1993; Weiss, 1978).

But given the broader policy context, not all scientists are equally positioned to engage in policy-oriented behaviors. Instead, a scientist's participation may depend on the scientist's network position. Therefore, beyond cultivating the content that emerges in a specific document, those who sponsor policy-oriented documents are inevitably shaping the social structure from which scientists' policy-oriented behavior emerges. This by-product social process can shape policy debates, ultimately contributing to the acceptance of one set of ideas over another (Kuhn, 1962).

Ken Frank, PhD, is a professor in Counseling, Educational Psychology and Special Education as well as in Fisheries and Wildlife at Michigan State University. His interests include the study of schools as organizations, social structures of students and teachers and school decision-making, and social capital. Dr. Frank's current projects include a study of how schools respond to the accountability standards of No Child Left Behind, how junior teachers are inculcated into the profession of teaching, how adolescents respond to their social contexts in schools, and how the decisions about natural resource use in small communities are embedded in social contexts.

I-Chien Chen is a graduate student in the Department of Sociology at Michigan State University. Her interests include the study of social capital on students' status attainment and well-being, knowledge diffusion, and coordinated behavior of children care organizations. Her current projects include a study of how adolescent subgroup networks influence aspiration and college attendance, how interorganizational network improved the effectiveness of resources and information coordination, and how scientific knowledge of climate change engage and diffuse in Great Lake Region. Her work has appeared in Taiwanese Journal of Sociology, International Journal of Internet and Enterprise Management, and Journal of Library and Information Science.

Youngmi Lee is an assistant professor in the Department of Public Administration at Kyonggi University. Her research focuses on local economic development policy, network management and leadership, collaborative governance, and social network analysis. Her work has appeared in Public Administration Review, Policy Studies Journal, and Internal Review of Public Administration.

Scott Kalafatis is a Ph.D. student at the School of Natural Resources and the Environment at the University of Michigan. He holds an M.S. degree in Environmental Policy and Planning and an M.U.P. in Economic Development from the University of Michigan. His research focuses on the facilitation of the use of climate science in policymaking and the cultivation of adaptive capacity. 
Tingqiao Chen is a graduate student in the College of Education at Michigan State University. Her major is Measurement and Quantitative Methods. She is currently working on a project studying dissemination of climate change knowledge among educators in the Great Lakes region.

Yun-Jia Lo is a doctoral student in Measurement and Quantitative Methods from College of Education and a consultant in Center of Statistical Training and Consulting at Michigan State University. She is also a research associate in the project "Useful to Usable (U2U): Transforming Climate Variability and Change Information for Cereal Crop Producers." Her research focuses on causal inference models and social network analysis. Her work has appeared in Journal of the National Medical Association, American Journal of Physical Anthropology, American Journal of Human Biology, and Evolution and Human Behavior.

Maria Carmen Lemos is Professor of Natural Resources and Environment at the University of Michigan, Ann Arbor. She is also a Senior Policy Analyst with the Udall Center for Studies of Public Policy. She has a PhD in Political Science from the Massachusetts of Technology (MIT) and focuses her research on public policymaking in Latin America and the U.S., especially related to the human dimensions of global change, the co-production of science and policy, and the role of technocrats and scientific knowledge in policymaking. In recent years, a substantial portion of this research has been applied to the areas of adaptive capacity building and adaptation to climate change, especially in the areas of water management, agriculture, and urban planning.

\section{Notes}

1. See for example the National Research Council report "Informing Decisions in a Changing Climate" (2009); see also "Groups Call for Scientists to Engage the Body Politic," New York Times (2011).

2. Information for three actors was not available to score the tendencies of advocacy and policy advising regarding climate change. Therefore, in models of policy advocacy and involvement, our sample was 76. However, all 79 actors are included in the network visualization in Figure 1.

3. To represent our results, we extend Field et al.'s (2006) application of multidimensional scaling (MDS) to embed cluster boundaries in a sociogram.

4. Calculations based on estimated effect of bridger without controlling for cluster or sector, although calculations are very similar with the controls.

\section{References}

Abbott, Andrew. 1998. "The Causal Devolution." Sociological Methods and Research 27: 148-81.

Actor 649. 2010. "Adaptation to the Impacts of Climate Change on Transportation." National Academy of Engineering [online]. http:/ / www.nae.edu/Publications/Bridge/24514/24525.aspx. Accessed June $18,2012$.

Balla, Steven J. 2001. "Interstate Professional Associations and the Diffusion of Policy Innovations." American Politics Research 29: 221-45.

Berardo, Ramiro, and John T. Scholz. 2010. “Self-Organizing Policy Networks: Risk, Partner Selection, and Cooperation in Estuaries." American Journal of Political Science 54: 632-49.

Bolin, Bert. 2007. A History of the Science and Politics of Climate Change: The Role of the Intergovernmental Panel on Climate Change. Cambridge: Cambridge University Press.

Burt, Ronald S. 1992. Structural Holes: The Social Structure of Competition. Cambridge, MA: Harvard University Press.

- 2001. "The Network Structure of Social Capital." In Research in Organizational Behavior, ed. R. S. Burt, B. M. Staw, and R. I. Sutton. Amsterdam: Elsevier Science JAI, pp. 345-423. 
- 2005. Brokerage and Closure. Oxford: Oxford University Press.

- 2007. "Secondhand Brokerage: Evidence of the Importance of Local Structure for Managers, Bankers, and Analysts." Academy of Management Journal 50 (1): 119-48.

Cook, Karen S., and Joseph M. Whitmeyer. 1992. "Two Approaches to Social Structure: Exchange Theory and Network Analysis." Annual Review of Sociology 18: 109-27.

Copas, John B., and H. G. Li. 1997. "Inference for Non-Random Samples.” Journal of the Royal Statistical Society, Series B (Methodological) 59 (1): 55-95.

Davis, Gerald F., Doug McAdam, W. Richard Scott, and Mayer N. Zald, eds. 2005. Social Movements and Organizations. New York: Cambridge University Press.

Diani, Mario. 2003. “'Leaders' or 'Brokers'? Positions and Influence in Social Movement Networks.” In Social Movements and Networks, ed. M. Diani, and D. McAdam. Oxford: Oxford University Press, 105-22.

Diani, Mario, and Doug McAdam, eds. 2003. Social Movements and Networks: Relational Approaches to Collective Action. Oxford: Oxford University Press.

Dilling, Lisa, and Maria Carmen Lemos. 2011. Creating usable science: Opportunities and constraints for climate knowledge use and their implications for science policy. Global Enviromental Change 21: 680-89.

Durkheim, Emile. 1964. The Division of Labor in Society. New York: Free Press.

- 1965. The Elementary Forms of Religious Life. New York: Free Press. 1966. Moral Education. New York: Free Press.

Field, Sam, Kenneth A. Frank, Kathryn Schiller, Catherine Riegle-Crumb, and Chanda Muller. 2006. "Identifying Social Contexts in Affiliation Networks: Preserving the Duality of People and Events." Social Networks 28: 97-123.

Frank, Kenneth. 1995. "Identifying Cohesive Subgroups." Social Networks 17: 27-56.

- 2000. "Impact of a Confounding Variable on the Inference of a Regression Coefficient." Sociological Methods and Research 29 (2): 147-94.

Frank, Kenneth A., Yong Zhao, and K. Borman. 2004. "Social Capital and the Diffusion of Innovations within Organizations: Application to the Implementation of Computer Technology in Schools." Sociology of Education 77: 148-71.

Giddens, Anthony. 1982. Profiles and Critiques in Social Theory. Berkeley, CA: University of California Press. . 1984. The Constitution of Society. Berkeley, CA: University of California Press.

Gould, Roger V., and Roberto M. Fernandez. 1989. "Structures of Mediation: A Formal Approach to Brokerage in Transaction Networks." Sociological Methodology 19: 89-126.

Homans, George C. 1950. The Human Group. New York: Harcourt Brace and Company.

IPCC. 2001. IPCC Third Assessment Report: Climate Change 2001 (TAR). Cambridge: Cambridge University Press.

_ 2007. IPCC Fourth Assessment Report: Climate Change 2007 (AR4). Cambridge: Cambridge University Press.

Jenkins-Smith, Hank, and Paul Sabatier. 1994. “Evaluating the Advocacy Coalition Framework." Journal of Public Policy 14: 175-203.

Kingdon, John W. 1984. Agendas, Alternatives, and Public Policies. Ann Arbor: University of Michigan Press.

-1995. Agendas, Alternatives and Public Policies, 2nd ed. Boston: Little, Brown \& Co.

Kuhn, Thomas. 1962. The Structure of Scientific Revolutions. Chicago: University of Chicago Press.

Lemos, Maria C., and Scott Kalafatis. 2011. "Integrating Climate Knowledge and Decision-Making in the Great Lakes." Public Presentation: Practical Solutions for a Warming World: AMS Conference on Climate Adaptation, Asheville, NC, July 19, 2011 [online]. http://ams.confex.com/ams/19Applied/ webprogram/Paper190711.html. Accessed June 18, 2012.

Lemos, Maria C., and Barbara Morehouse. 2005. "The Co-Production of Science and Policy in Integrated Climate Assessments." Global Environmental Change 15: 57-68. 
Mintrom, Michael. 1997. "Policy Entrepreneurs and the Diffusion of Innovation." American Journal of Political Science 41 (3): 738-70.

Mintrom, Michael, and Phillipa Norman. 2009. "Policy Entrepreneurship and Policy Change." The Policy Studies Journal 37 (4): 649-67.

Mintrom, Michael, and Sandra Vergari. 1998. "Policy Networks and Innovation Diffusion: The Case of State Education Reforms." Journal of Politics 60: 126-48.

Monteleone, Mark. 2011. "Generic Questions for Interviewing Stakeholders." Business Analysis E Systems Analysis [online]. http://www.modernanalyst.com/Resources/Articles/tabid/115/Default.aspx? ArticleType=ArticleView\&ArticleID=1087. Accessed June 18, 2012.

Montpetit, Eric. 2011. "Scientific Credibility, Disagreement, and Error Cost in 17 Biotechnology Policy Subsystems." Policy Studies Journal 39: 513-33.

National Research Council. 2009. Informing Decisions in a Changing Climate. Panel on Strategies and Methods for Climate-Related Decision Support, Committee on the Human Dimensions of Global Change. Division of Behavioral and Social Sciences and Education. Washington, DC: The National Academies Press.

New York Times. 2011. "Groups Call for Scientists to Engage the Body Politic." August 8. [online]. http://www.nytimes.com/2011/08/09/science/09emily.html?_r=1\&ref=todayspaper. Accessed June 18, 2012.

Nisbet, Matthew C. 2009. "Communicating Climate Change Why Frames Matter for Public Engagement." Environment 51 (2): 12-23.

Oreskes, Naomi. 2011. "The Doubt Fighter." Nature Climate Change 1: 239-40. [online]. http://www. nature.com/nclimate/journal/v1/n5/full/nclimate1183.html. Accessed June 18, 2012.

Parsons, Talcott. 1949. The Structure of Social Action. Glencoe, IL: Free Press.

Pielke, Roger A., Jr., and Daniel Sarewitz. 2003. "Wanted: Scientific Leadership on Climate." Issues in Science and Technology Winter: 27-30.

Polsby, Nelson W. 1984. Political Innovation in America: The Politics of Policy Initiation. New Haven, CT: Yale University Press.

Rawls, John. 1971. A Theory of Justice. Cambridge, MA: Belknap Press.

Roberts, Nancy, and Paula King. 1991. "Policy Entrepreneurs: Their Activity Structure and Function in the Policy Process." Journal of Public Administration Research and Theory 1 (2): 147-75.

Robins, James, Andrea Rotnitzky, and Daniel Scharfstein. 2000. "Sensitivity Analysis for Selection Bias and Unmeasured Confounding in Missing Data and Causal Inference Models." In Statistical Models for Epidemiology, the Environment, and Clinical Trials, ed. E. Halloran, and D. Berry. New York: Springer-Verlag, 1-95.

Rosenbaum, Paul R., and Donald B. Rubin. 1983. “The Central Role of the Propensity Score in Observational Studies for Causal Effects." Biometrika 70 (1): 41-55.

Sabatier, Paul, and Hank Jenkins-Smith, eds. 1993. Policy Change and Learning: An Advocacy Coalition Approach. Boulder, CO: Westview Press.

Sabatier, Paul A., and Mathew Zafonte. 2001. Policy knowledge, advocacy organizations. In International encyclopedia of the social and behavioral sciences, ed. N. Smelser and P. Baltes, 11563-68. New York: Elsevier Science.

Sewell, William H. 1992. "A Theory of Structure: Duality, Agency, and Transformation." American Journal of Sociology 98 (1): 1-29.

Simon, H. A. 1965. "The Architecture of Complexity." Proceedings of the American Philosophical Society 106 (6): 467-82.

Skvoretz, John, and Katherine Faust. 1999. "Logit Models for Affiliation Networks." Sociological Methodology 29: 253-78.

True, Jacqui, and Michael Mintrom. 2001. "Transnational Networks and Policy Diffusion: The Case of Gender Mainstreaming." International Studies Quarterly 45: 27-57.

Tunnicliffe Wilson, Granville. 2010. "Atmospheric CO2 and Global Temperatures: The Strength and Nature of Their Dependence." Public Presentation: NBER—NSF Time Series Conference. Duke University. 
Valente, Thomas W. 1995. Network Models of the Diffusion of Innovations. Cresskill, NJ: Hampton Press.

Wang, Peng, Ken Sharpe, Philippa Pattison, and Garry Robins. 2009. “Exponential Random Graph (P*) Models for Affiliation Networks." Social Networks 31: 12-25.

Weible, Christopher, Paul Sabatier, and Mark Lubell. 2004. "A Comparison of a Collaborative and TopDown Approach to the Use of Science in Policy: Establishing Marine Protected Areas in California." Policy Studies Journal 32 (2): 187-207.

Weiss, Carol H. 1978. "Improving the Linkage between Social Research and Public Policy." In Knowledge and Policy: The Uncertain Connection, ed. L. E. Lynn. Washington, DC: National Academy of Science.

Wrong, Dennis H. 1961. "The Oversocialized Conception of Man in Modern Sociology." The American Sociological Review 26 (2): 183-93.

\section{Appendix A: Interview Questionnaire}

a) What collaborative and individual efforts have you made to provide scientific information related to climate change to decision makers?

b) Why did you participate in these activities? (I will list if necessary)

a. If they appear to be mentioning a network or other recognized set of relationships:

i. How do you think about the role of networks to influence your political activities or behaviors?

ii. Have you interacted across different groups that collaborate with each other more than they do with others outside of their group?

iii. Has your experience of working between different groups influenced your perspective on climate change or your interest in engaging decision makers?

c) Do you see yourself as advisor, advocate or both when you were participating? How do you define the two?-Maintain a boundary between them?

d) Thinking about collaborative efforts in which you interacted with decision makers, how has your involvement in the production of these documents influenced:

a. The research that you are doing

b. Your level of engagement on climate change issues

c. Your ability to provide assistance to those who are considering climate change when making policy decisions

e) Over the next several questions, we would like you to provide some description of the process of producing these documents:

a. Who was involved

b. How often were you in contact with other participants? 
c. What form of communication was used?

d. How did the amount and form of communication vary between participants?

f) What kind of climate information do you think decision makers are looking for?

g) How do you think that these decision makers will use climate information?

h) Who are the most influential developers of climate information concerning the Great Lakes Region?-these can be people or organizations

i) Who are the most influential communicators of climate information in the Great Lakes Region?- these can be people or organizations

j) Who do you go to when looking for information concerning climate change?

k) What other groups are you involved in that are interested in climate change?

1) Tell me about a change that you've made recently in your approach to your climate-change related research

a. Why did you make this change?

b. Who influenced this decision? (people or organizations)

\section{Appendix B: Documents by Cluster}

\section{- $\quad$ Cluster 1}

- 20040: Preparing for a Changing Climate: The Potential Consequences of Climate Variability and Change in the Great Lakes Region

- 20002: Adapting to Climate Change and Variability in the Great Lakes-St. Lawrence Basin

- 20038: Preface to the Potential Impacts of Climate Change in the Great Lakes Region

- 20023: From Impacts to Adaptation: Canada in a Changing Climate 2007

- Cluster 2

- 20015: Confronting Climate Change in the Great Lakes Region: Impacts on Our Communities and Ecosystems

- 20016: Confronting Climate Change in the Great Lakes Region

- 20011: Climate Change in the Great Lakes Region: Starting a Public Discussion

- 20021: Ecological Impacts of Climate Change

- 20025: Global Climate Change Impacts in the US: A State of Knowledge Report from the U.S. Global Change Research Program 
- 20031: Informing Decisions in a Changing Climate: Panel on Strategies and Methods for Climate-Related Decision Support

- 20032: Introduction: Assessing the Effects of Climate Change on Chicago and the Great Lakes

- 20037: Potential Impacts of Climate Change on U.S. Transportation

- 20039: Chicago Climate Action Plan

- 20044: Scientific Assessment of the Effects of Global Climate on the United States

- 20059: Economic Impacts of Climate Change on Pennsylvania

- Cluster 3

- 20009: Climate Change Impacts and Adaptation: A Canadian Perspective

- 20003: Adapting to Climate Change in Ontario: Towards the Design and Implementation of a Strategy and Action Plan (Report of the Expert Panel on Climate Change Adaptation)

- 20033: IPCC 4th Assessment Report, Working Group II Report "Impacts, Adaptation and Vulnerability" North America, Chapter 14. 